\title{
Endothelin-1 downregulates Mas receptor expression in human cardiomyocytes
}

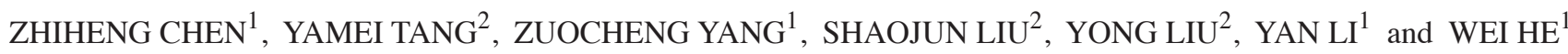 \\ ${ }^{1}$ Department of Pediatrics, The Third Xiangya Hospital, Central South University, Changsha, Hunan 410013; \\ ${ }^{2}$ Department of Clinical Laboratory, The Second Xiangya Hospital, Central South University, \\ Changsha, Hunan 410011, P.R. China
}

Received March 22, 2013; Accepted June 27, 2013

DOI: $10.3892 / \mathrm{mmr} .2013 .1577$

\begin{abstract}
Endothelin-1 (ET-1) and the renin-angiotensin system (RAS) are involved in the pathogenesis of cardiac dysfunction. The Mas receptor is a functional binding site for angiotensin (Ang)-(1-7), which is now considered a critical component of the RAS and exerts cardioprotective effects. To the best of our knowledge, the present study aimed to examine, for the first time, the effects of ET-1 on Mas expression in cultured human cardiomyocytes. Human cardiomyocytes were treated with ET-1 at different concentrations $(1,5,10$, 20 and $30 \mathrm{nM})$ for varied time periods $(0.5,1.5,3,4.5$ or $6 \mathrm{~h})$ with or without the transcription inhibitor actinomycin D, endothelin A (ETA) receptor blocker BQ123 and ETB receptor blocker BQ788, or different kinase inhibitors. ET-1 decreased the Mas mRNA level in a statistically significant dose- and time-dependent manner within $4.5 \mathrm{~h}$, which was reflected in the dose-dependent downregulation of Mas promoter activity, Mas protein levels and Ang-(1-7) binding on the cell membrane. Actinomycin D (1 mg/ml), BQ123 $(1 \mu \mathrm{M})$, p38 mitogen-activated protein kinase (MAPK) siRNA and inhibitor PD169316 (25 $\mu \mathrm{M})$, completely eliminated the inhibitory effects of ET-1 on Mas expression in human cardiomyocytes. In conclusion, the present study demonstrated that ET-1 downregulates Mas expression at the transcription level in human cardiomyocytes via the ETA receptor by a p38 MAPK-dependent mechanism. This study provides novel insights into the function of ET-1 and the Ang-(1-7)/Mas axis in cardiac pathophysiology.
\end{abstract}

\section{Introduction}

The renin-angiotensin system (RAS) is crucial for cardiovascular regulation (1). In the RAS, angiotensin-converting

Correspondence to: Professor Yamei Tang, Department of Clinical Laboratory, The Second Xiangya Hospital, Central South University, 139 People's Road, Changsha, Hunan 410011, P.R. China E-mail: tayame139@yahoo.com.cn

Key words: endothelin-1, endothelin A receptor, Mas receptor, cardiomyocytes, angiotensin-(1-7), angiotensin-converting enzyme 2 , angiotensin II, p38 mitogen-activated protein kinase enzyme (ACE) metabolizes angiotensin I (Ang I) to form angiotensin II (Ang II), which exerts direct trophic actions on cardiac cells through the AT1 receptor, inducing cardiomyocyte hypertrophy and fibroblast proliferation (1). Local Ang II production is of key importance in the pathophysiology of the RAS in the heart (2). Gradual increases in cardiac Ang II levels have been demonstrated in experimental models and clinically during the development of heart failure (3).

In addition to the ACE/Ang II/AT1 receptor axis, the RAS possesses a counter-regulatory axis comprising ACE2, Ang-(1-7) and the Mas receptor (4). Ang-(1-7) is now recognized as a critical component of the RAS, as it exerts a vast array of actions, many of which oppose the actions of Ang II (5). Ang-(1-7) is generated directly from Ang II by ACE2 with high efficiency (5-7) and also directly from Ang I by neutral endopeptidase and prolylendopeptidase $(8,9)$. Recently it was indicated that the heart and blood vessels are the main targets for the actions of Ang-(1-7) (10). These actions include biochemical and functional alterations that result in vasodilation and improved cardiac function (11). It is now well established that the $\mathrm{G}$ protein-coupled receptor Mas, is a functional binding site for Ang-(1-7) (10,11). The Mas receptor is present in human cardiomyocytes (12) and mediates most of the known cardioprotective effects of Ang-(1-7), such as vasodilatation, anti-fibrosis, -hypertrophic and -proliferative effects (4). The Ang-(1-7)/Mas axis has been considered a potential target for the development of novel cardiovascular treatment agents (11).

Endothelin-1 (ET-1) is a potent endothelial cell-derived venous and arterial vasoconstrictor peptide that functions as a circulating hormone and a paracrine factor in the regulation of cardiovascular mechanisms (13). ET-1 is responsible for a variety of cell events, such as contraction, proliferation and apoptosis. These effects occur following the activation of the endothelin receptors ETA and ETB, which are present on cardiomyocytes, fibroblasts, smooth muscle cells, endothelial cells, and glomerular and tubular cells of the kidney (13). ET-1 levels are increased in patients with heart disease, particularly in acute myocardial infarction or congestive heart diseases, as well as in renal dysfunction (14). In heart failure, ET-1 levels have been demonstrated to increase in parallel with the functional capacity and severity of the disease $(15,16)$. 
According to previous studies (?), ET-1 and the Ang-(1-7)/Mas axis are important for cardiac dysfunction. To the best of our knowledge, the present study examined, for the first time, the effects of ET-1 on Mas expression in cultured human cardiomyocytes, aiming to provide indepth insights into the function of ET-1 and the Ang-(1-7)/Mas axis in cardiac pathophysiology.

\section{Materials and methods}

Reagents. ET-1, Ang-(1-7), actinomycin D, and kinase inhibitors LY294002, Go6983, PD098059 and PD169316, were purchased from Sigma (St. Louis, MO, USA). ${ }^{125}$ I-Sodium iodide (carrier free, $100 \mathrm{mCl} / \mathrm{ml}$ ) was purchased from Amersham Biosciences (Piscataway, NJ, USA). In addition, TRIzol reagent for RNA isolation and the SYBR-Green Master Mix were purchased from Invitrogen Life Technologies (Carlsbad, CA, USA) and Applied Biosystems (Foster City, CA, USA), respectively. Anti-MAS1 (N-15) antibody was purchased from Santa Cruz Biotechnology, Inc. (sc-54682; Santa Cruz, CA, USA). Furthermore, anti-phospho-p38 (Thr180/Tyr182) (\#9212) and anti-p38 (\#8690) antibodies were purchased from Cell Signaling Technology, Inc. (Danvers, MA, USA). To silence the p38 MAPK gene expression, siRNA oligonucleotides with the following sequence were designed; p38 siRNA, 5'-GAAGCTCTCCAGACCATTT-3'. Human Mas promoter-luciferase reporter construct (\#S718157) and LightSwitch assay reagents were purchased from SwitchGear Genomics (Menlo Park, CA, USA). Lipofectamine 2000 transfection reagent was purchased from Invitrogen.

Cell culture and treatment. Human adult cardiomyocytes (no. 6210) and cardiomyocyte medium (CMM no. 6201), were purchased from ScienCell Research Laboratories (Carlsbad, CA, USA). The cells were treated with ET-1 at different concentrations $(1,5,10,20$ and $30 \mathrm{nM})$ for varied time periods $(0.5,1.5,3,4.5$ or $6 \mathrm{~h})$ in the presence or absence of BQ123 $(1 \mu \mathrm{M})$ or BQ788 $(1 \mu \mathrm{M})$. Actinomycin D and all kinase inhibitors were dissolved in dimethyl sulfoxide (DMSO; final concentration, 0.05\%). For kinase inhibitor treatment, human cardiomyocytes were pretreated with the kinase inhibitor for $30 \mathrm{~min}$ and then incubated with the kinase inhibitor and ET-1 $(30 \mathrm{nM})$ for $4.5 \mathrm{~h}$. Human cardiomyocytes treated with ET-1 $(30 \mathrm{nM})$ and DMSO $(0.05 \%)$ were used as a control in the experiments. For actinomycin $\mathrm{D}$ treatment, the cells were pretreated with actinomycin $\mathrm{D}(1 \mathrm{mg} / \mathrm{ml})$ for $30 \mathrm{~min}$, and then cultured for $1.5,3$ or $4.5 \mathrm{~h}$ in medium containing actinomycin D $(1 \mathrm{mg} / \mathrm{ml})$ with or without ET-1 $(30 \mathrm{nM})$. The cells treated with DMSO $(0.05 \%)$ were used as a control.

$q P C R$. RNA was prepared using TRIzol reagent followed by purification with TURBO DNA-free ${ }^{\mathrm{TM}}$ kit (Ambion, Austin, TX, USA). The cDNAs were synthesized using SuperScript II reverse transcriptase (Invitrogen). qPCR was performed on an ABI Prism 7700 Sequence Detection System, with use of the fluorescent dye SYBR-Green Master Mix (Applied Biosystems) following the manufacturer's instructions. The results were normalized against that of the housekeeping gene glyceraldehyde-3-phosphate dehydrogenase $(G A P D H)$ in the same sample. The primers used were as follows: Human
Mas, 5'-TTCCGGATGAGAAGAAATCC-3' (forward) and 5'-ATGGCCAGAAGAAAGCTCAT-3' (reverse); and human GAPDH, 5'-GTCAGTGGTGGACCTGACCT-3' (forward) and 5'-TGCTGTAGCCAAATTCGTTG-3' (reverse). The mRNA level of treated cells was shown as fold changes to that of untreated control cells (designated as 1). Each experiment was repeated three times in triplicate. Results are expressed as the mean \pm standard deviation.

Luciferase assay. Human cardiomyocytes were transfected with human Mas promoter-luciferase reporter constructs (SwitchGear Genomics) using Lipofectamine 2000 transfection reagent (Invitrogen) and then treated with ET-1 (10 or $30 \mathrm{nM}$ ) for $4.5 \mathrm{~h}$. Luciferase assays were performed $24 \mathrm{~h}$ later with LightSwitch assay reagents (SwitchGear Genomics) according to the manufacturer's instructions. Each experiment was repeated three times in duplicate. Untreated human cardiomyocytes were used as a control.

Western blot analysis. Human cardiomyocytes were lysed in $250 \mu \mathrm{l}$ of $2 \mathrm{X}$ sodium dodecyl sulphate (SDS) loading buffer $(62.5 \mathrm{mM}$ Tris $\mathrm{HCl}, \mathrm{pH} 6.8,2 \%$ SDS, $25 \%$ glycerol, $0.01 \%$ bromphenol blue and 5\% 2-mercaptoethanol) and incubated at $95^{\circ} \mathrm{C}$ for $10 \mathrm{~min}$. An equal volume of proteins $(100 \mu \mathrm{g})$ for each sample was separated by 8-15\% SDS-polyacrylamide gel and blotted onto a polyvinylidene difluoride microporous membrane (Millipore, Billerica, MA, USA). The membranes were incubated for $1 \mathrm{~h}$ at a 1:1000 dilution of the primary antibody and then washed and revealed using secondary antibodies with horseradish peroxidase conjugate (1:5000, $1 \mathrm{~h})$. Peroxidase was revealed with a GE Healthcare enhanced chemiluminescence kit. Proteins were quantified prior to being loaded onto the gel.

( ${ }^{125}$ I)Ang-(1-7) binding assay. Human cardiomyocytes in 12-well plates were rinsed two times with DMEM and equilibrated on ice with incubation buffer (DMEM containing $0.2 \%$ bovine serum albumin and a protease inhibitor cocktail, pH 7.4) for $30 \mathrm{~min}$. Subsequently, the plates were incubated at $4^{\circ} \mathrm{C}$ for $60 \mathrm{~min}$ with incubation buffer containing $0.5 \mathrm{nmol} / 1{ }^{125} \mathrm{I}$-Ang-(1-7) (17). Incubation was stopped by rinsing the cells three times with ice-cold phosphate-buffered saline. Cells were solubilized by incubation with $0.1 \mathrm{~mol} / 1$ $\mathrm{NaOH}$ for 60 min and the radioactivity was measured. Non-specific binding was determined in the presence of $10 \mu \mathrm{mol} / 1$ unlabeled Ang-(1-7), which was no higher than $15 \%$. Specific binding was calculated by the subtraction of non-specific binding from total binding. The disintegrations per min (dpm) data were normalized against the cell number (per 20000 cells) and shown as a percentage of that of untreated control cells (designated as 100\%). Each experiment was repeated three times in triplicates. Results are expressed as the mean \pm standard deviation.

Statistical analysis. Statistical analysis was performed with SPSS software, for Windows version 10.0 (SPPS, Inc., Chicago, IL, USA). Data values were expressed as the mean \pm standard deviation. Comparison of means among multiple groups was performed with one-way analysis of variance (ANOVA) followed by post-hoc pairwise comparisons using Tukey's 
Table I. Relative Mas mRNA levels in human cardiomyocytes in the presence of endothelin-1 (ET-1) with or without ET receptor blockers.

Time (h)

\begin{tabular}{|c|c|c|c|c|c|}
\hline ET-1 (nm) & 0.5 & 1.5 & 3 & 4.5 & 6 \\
\hline 1 & $0.99 \pm 0.02$ & $1.01 \pm 0.03$ & $0.98 \pm 0.02$ & $0.98 \pm 0.03$ & $0.96 \pm 0.04$ \\
\hline 5 & $0.99 \pm 0.02$ & $0.87 \pm 0.03^{\mathrm{a}, \mathrm{d}}$ & $0.59 \pm 0.04^{\mathrm{a}, \mathrm{d}, \mathrm{e}}$ & $0.38 \pm 0.05^{\mathrm{a}, \mathrm{d}, \mathrm{e}, \mathrm{f}}$ & $0.38 \pm 0.04^{\mathrm{a}, \mathrm{d}, \mathrm{e}, \mathrm{f}}$ \\
\hline 10 & $0.98 \pm 0.05$ & $0.52 \pm 0.05^{\mathrm{a}, \mathrm{b}, \mathrm{d}}$ & $0.37 \pm 0.03^{\mathrm{a}, \mathrm{b}, \mathrm{d}, \mathrm{e}}$ & $0.26 \pm 0.03^{\mathrm{a}, \mathrm{b}, \mathrm{d}, \mathrm{e}, \mathrm{f}}$ & $0.25 \pm 0.02^{\mathrm{a}, \mathrm{b}, \mathrm{d}, \mathrm{e}, \mathrm{f}}$ \\
\hline 20 & $0.97 \pm 0.04$ & $0.39 \pm 0.05^{\mathrm{a}, \mathrm{b}, \mathrm{c}, \mathrm{d}}$ & $0.25 \pm 0.03^{\mathrm{a}, \mathrm{b}, \mathrm{c}, \mathrm{d}, \mathrm{e}}$ & $0.14 \pm 0.05^{\mathrm{a}, \mathrm{b}, \mathrm{c}, \mathrm{d}, \mathrm{e}, \mathrm{f}}$ & $0.14 \pm 0.03^{\mathrm{a}, \mathrm{b}, \mathrm{c}, \mathrm{d}, \mathrm{e}, \mathrm{f}}$ \\
\hline 30 & $0.96 \pm 0.03$ & $0.35 \pm 0.04^{\mathrm{a}, \mathrm{b}, \mathrm{c}, \mathrm{d}}$ & $0.20 \pm 0.04^{\mathrm{a}, \mathrm{b}, \mathrm{c}, \mathrm{d}, \mathrm{e}}$ & $0.11 \pm 0.02^{\mathrm{a}, \mathrm{b}, \mathrm{c}, \mathrm{d}, \mathrm{e}, \mathrm{f}}$ & $0.10 \pm 0.04^{\mathrm{a}, \mathrm{b}, \mathrm{c}, \mathrm{d}, \mathrm{e}, \mathrm{f}}$ \\
\hline \multicolumn{6}{|l|}{$30+B Q 123$} \\
\hline $\begin{array}{l}(1 \mu \mathrm{M}) \\
30+\mathrm{BQ} 788\end{array}$ & $1.05 \pm 0.04$ & $1.05 \pm 0.05$ & $1.07 \pm 0.03$ & $1.08 \pm 0.07$ & $1.10 \pm 0.03$ \\
\hline$(1 \mu \mathrm{M})$ & $0.96 \pm 0.06$ & $0.38 \pm 0.05^{\mathrm{a}, \mathrm{b}, \mathrm{c}, \mathrm{d}}$ & $0.25 \pm 0.04^{\mathrm{a}, \mathrm{b}, \mathrm{c}, \mathrm{d}, \mathrm{e}}$ & $0.15 \pm 0.03^{\mathrm{a}, \mathrm{b}, \mathrm{c}, \mathrm{d}, \mathrm{e}, \mathrm{f}}$ & $0.13 \pm 0.05^{\mathrm{a}, \mathrm{b}, \mathrm{c}, \mathrm{d}, \mathrm{e}, \mathrm{f}}$ \\
\hline
\end{tabular}

Mas mRNA levels of treated cells were shown as fold changes to that of untreated control cells (designated as 1). Comparison of the means among all the experimental groups was performed with one-way analysis of variance followed by post-hoc pairwise comparisons using Tukey's tests. ${ }^{\mathrm{a}} \mathrm{P}<0.05$ compared with ET- 1 treatment at $1 \mathrm{nM}$ or ET-1 $(30 \mathrm{nM})$ and BQ123 $(1 \mu \mathrm{M}) ;{ }^{b} \mathrm{P}<0.05$ compared with ET- 1 treatment at $5 \mathrm{nM}$; ${ }^{\mathrm{C}} \mathrm{P}<0.05$ compared with ET- 1 treatment at $10 \mathrm{nM} ;{ }^{\mathrm{d}} \mathrm{P}<0.05$ compared with $0.5 \mathrm{~h}$ of ET-1 treatment at each concentration; ${ }^{\mathrm{e}} \mathrm{P}<0.05$ compared with $1.5 \mathrm{~h}$ of ET-1 treatment at each concentration and ${ }^{\mathrm{f}} \mathrm{P}<0.05$ compared with $3 \mathrm{~h}$ of ET-1 treatment at each concentration.

tests. The significance level of this study was set at a two-tailed $\mathrm{P}=0.05$.

\section{Results}

Relative Mas mRNA levels in human cardiomyocytes in the presence of ET-1 with or without ET receptor blockers. Human cardiomyocytes were treated with ET-1 at different concentrations $(1,5,10,20$ and $30 \mathrm{nM})$ for varied time periods $(0.5,1.5$, $3,4.5$ or $6 \mathrm{~h}$ ). The Mas mRNA levels were examined using qPCR. The Mas mRNA level of treated cells was shown as fold changes to that of untreated control cells (designated as 1). As shown in Table I, ET-1 concentration of 5-20 nM, decreased the Mas mRNA level in a statistically significant dose- and time-dependent manner within $4.5 \mathrm{~h}$ of treatment, which was completely eliminated by selective ETA receptor blocker BQ123, but not by the selective ETB receptor blocker BQ788. ET-1 at $1 \mathrm{nM}$ had no significant effects on the Mas mRNA levels at all time points. Additionally, treatment for $0.5 \mathrm{~h}$ with ET-1 at 1-30 nM also showed no significant effects on the Mas mRNA level.

Effects of ET-1 on human Mas promoter activities and on Mas $m R N A$ level. To evaluate the effects of ET-1 on Mas mRNA stability, human cardiomyocytes were pretreated with transcription inhibitor actinomycin D $(1 \mathrm{mg} / \mathrm{ml})$ for $30 \mathrm{~min}$ and then cultured for $1.5,3$ or $4.5 \mathrm{~h}$ in medium containing actinomycin D (1 mg/ml), with or without ET-1 (30 nM).qPCR assays showed that the Mas mRNA level significantly decreased with time following actinomycin D treatment (Fig. 1). In the presence of actinomycin D, ET-1 had no significant effects on the Mas mRNA level at any of the time points (Fig. 1). The results suggest that ET-1 decreases Mas expression at the transcriptional level rather than decreasing Mas mRNA stability at the post-transcriptional level. This was confirmed by luciferase
Table II. Relative Mas mRNA levels in human cardiomyocytes in the presence of endothelin-1 (ET-1) with or without kinase inhibitors.

Treatment

Relative Mas mRNA level

\begin{tabular}{ll}
\hline Control & $0.11 \pm 0.02^{\mathrm{a}}$ \\
+LY294002 $(25 \mu \mathrm{M})$ & $0.21 \pm 0.12^{\mathrm{a}}$ \\
+Go6983 $(250 \mathrm{nM})$ & $0.18 \pm 0.06^{\mathrm{a}}$ \\
+PD098059 $(25 \mu \mathrm{M})$ & $0.20 \pm 0.08^{\mathrm{a}}$ \\
+PD169316 $(25 \mu \mathrm{M})$ & $1.11 \pm 0.07$ \\
\hline
\end{tabular}

Human cardiomyocytes were pretreated with the kinase inhibitor for $30 \mathrm{~min}$ and then incubated with the kinase inhibitor and ET-1 $(30 \mathrm{nM})$ for $4.5 \mathrm{~h}$. The kinase inhibitors were dissolved in dimethyl sulfoxide (DMSO; final concentration of DMSO 0.05\%). Human cardiomyocytes treated with ET-1 (30 nM) and DMSO $(0.05 \%)$ were used as the control. Mas mRNA level of treated cells was shown as fold changes to that of untreated control cells (designated as 1). Comparison of the means among the experimental groups was performed with one-way analysis of variance followed by post-hoc pairwise comparisons using Tukey's tests. ${ }^{\text {a }}<0.05$ compared with the ET-1 $(30 \mathrm{nM})$ and PD169316 $(25 \mu \mathrm{M})$ treatment.

assays, which showed that ET-1 had a dose-dependent inhibitory effect on human Mas promoter activity (Fig. 2A).

To determine the signaling pathways involved in the inhibitory effects of ET-1 on Mas gene transcription, we examined the Mas mRNA levels in human cardiomyocytes treated with ET-1 (30 nM) with or without different kinase inhibitors, for $4.5 \mathrm{~h}$. As shown in Table II, inhibition of protein kinase C (Go6983; $250 \mathrm{nM})$, MAPK (PD098059; $25 \mu \mathrm{M})$ and p38 kinase (LY294002; $25 \mu \mathrm{M}$ ), had no significant effects on the Mas mRNA level. By contrast, the inhibition of p38 


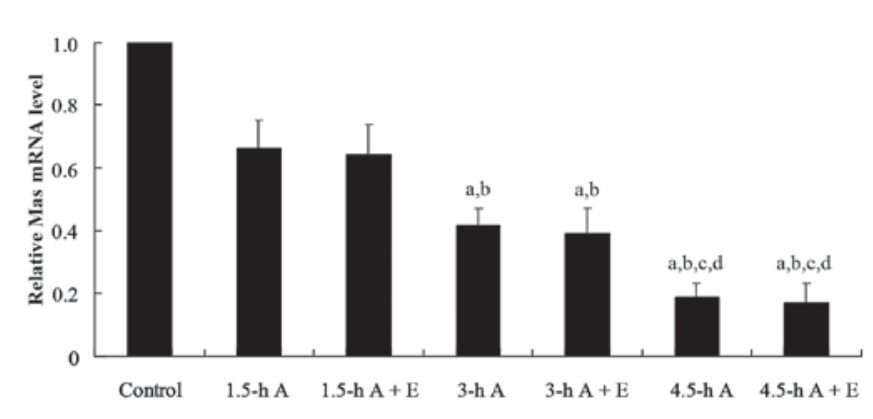

Figure 1. Mas receptor mRNA level in human cardiomyocytes treated with actinomycin D with or without endothelin-1 (ET-1). Human cardiomyocytes were pretreated with actinomycin $\mathrm{D}(1 \mathrm{mg} / \mathrm{ml})$ for $30 \mathrm{~min}$ and then cultured for $1.5,3$ or $4.5 \mathrm{~h}$ in medium containing actinomycin $\mathrm{D}(1 \mathrm{mg} / \mathrm{ml})$ with or without ET-1 (30 nM). Mas receptor mRNA level of treated cells was shown as fold changes to that of untreated control cells (designated as 1). A, actinomycin D and E, ET-1. ${ }^{a} \mathrm{P}<0.05$ compared with $1.5 \mathrm{~h} \mathrm{~A} ;{ }^{\mathrm{b}} \mathrm{P}<0.05$ compared with $1.5 \mathrm{~h} \mathrm{~A}$ and $\mathrm{E} ;{ }^{\mathrm{c}} \mathrm{P}<0.05$ compared with $3 \mathrm{~h} \mathrm{~A}$ and ${ }^{\mathrm{d}} \mathrm{P}<0.05$ compared with $3 \mathrm{~h} \mathrm{~A}$ and $\mathrm{E}$.

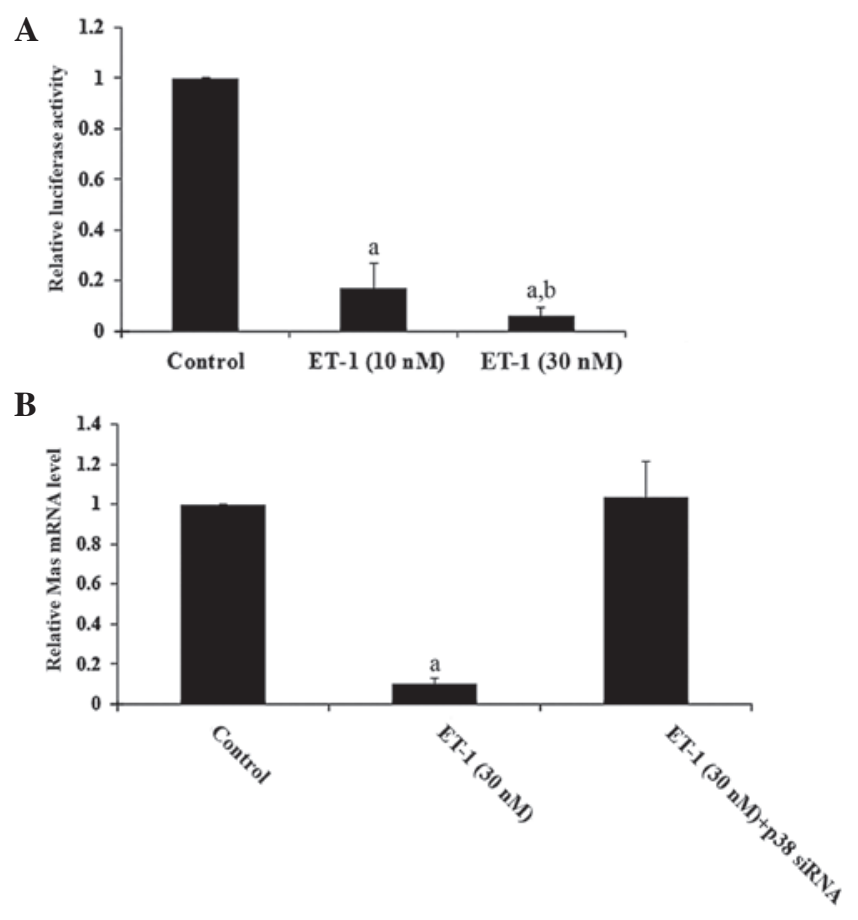

Figure 2. Effects of endothelin-1 (ET-1) on human Mas promoter activities and on Mas mRNA level in human cardiomyocytes treated with siRNA against p38 mitogen-activated protein kinase (MAPK). (A) Human cardiomyocytes were transfected with human Mas promoter-luciferase reporter plasmids and then treated with ET-1 (10 or $30 \mathrm{nM})$ for $4.5 \mathrm{~h}$. Twenty-four hours later, luciferase assays were performed. Luciferase activities were expressed as fold changes to that of untreated control cells (designated as 1). (B) Human cardiomyocytes with or without transfection of p38 MAPK siRNA were treated with ET-1 (30 nM) for $4.5 \mathrm{~h}$. Mas mRNA level of treated cells was shown as fold changes to that of untreated control cells (designated as 1). ${ }^{\text {a }} \mathrm{P}<0.05$ compared with untreated control cells and ${ }^{\mathrm{b}} \mathrm{P}<0.05$ compared with $10 \mathrm{~nm}$ ET-1 treatment.

MAPK by selective inhibitor PD169316 (25 $\mu \mathrm{M})$ completely eliminated the inhibitory effects of ET-1 on Mas gene transcription. We also employed siRNA to knock down p38 MAPK in human cardiomyocytes. As shown in Fig. 2B, while ET-1 (30 nM) decreased the Mas mRNA level by $>90 \%$, there were no significant effects on cardiomyocytes
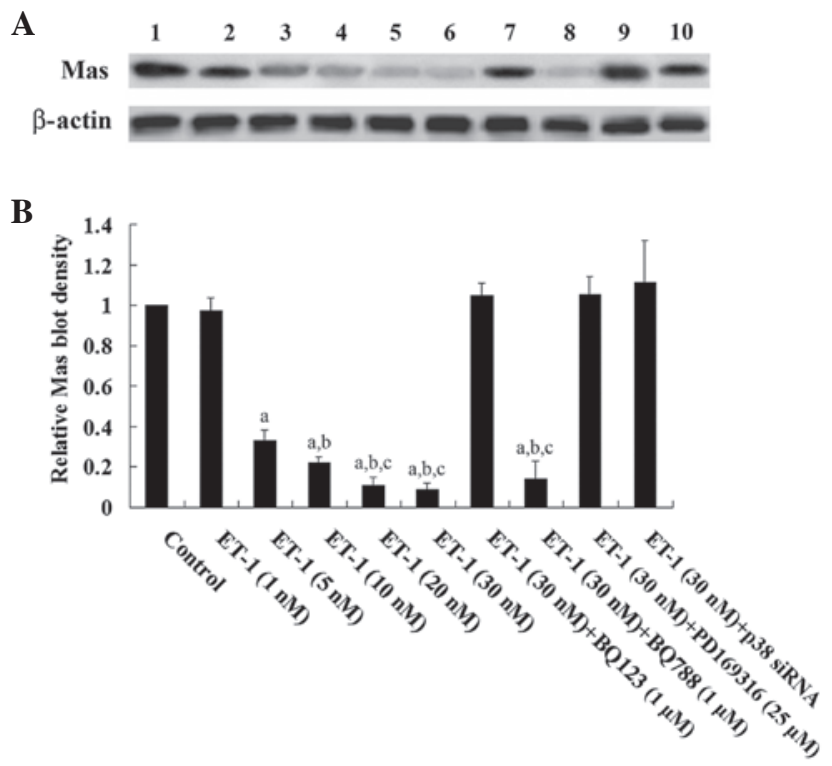

Figure 3. Western blot analysis of Mas expression in human cardiomyocytes. (A) Human cardiomyocytes were treated with ET-1 (1, 5, 10, 20 and $30 \mathrm{nM})$ with or without BQ123 $(1 \mu \mathrm{M}), \mathrm{BQ} 788(1 \mu \mathrm{m}), \mathrm{PD} 169316(25 \mu \mathrm{m})$ or p38 mitogen-activated protein kinase siRNA for $4.5 \mathrm{~h}$. Twenty-four hours later, cell lysates were subject to western blot analysis for Mas expression. Lysates from untreated human cardiomyocytes were used as a control (lane 1). Concentrations of ET-1 were as follows: Lane 2, $1 \mathrm{nM}$; lane 3, $5 \mathrm{nM}$; lane 4, $10 \mathrm{nM}$; lane 5, $20 \mathrm{nM})$; lane 6, $30 \mathrm{nM}$; lane 7, $30 \mathrm{nM}$ and BQ123 $(1 \mu \mathrm{M})$; lane 8, $30 \mathrm{nM}$ and BQ788 $(1 \mu \mathrm{M})$; lane 9,30 $\mathrm{nM}$ and PD169316 $(25 \mu \mathrm{M})$ and lane $10,30 \mathrm{nM}$ and $\mathrm{p} 38$ siRNA. $\beta$-actin blotting was used as a loading control. (B) Mas and $\beta$-actin blots were measured by densitometry. The density of the Mas blot was normalized against that of $\beta$-actin to obtain a relative density, which was expressed as fold changes to the relative Mas density of untreated control cells (designated as 1 ). ${ }^{\text {a }} \mathrm{P}<0.05$ compared with untreated control cells; ${ }^{b} \mathrm{P}<0.05$ compared with $5 \mathrm{~nm}$ ET-1 treatment and ${ }^{\mathrm{c}} \mathrm{P}<0.05 \mathrm{com}-$ pared with $10 \mathrm{~nm}$ ET-1 treatment.

transfected with p38 (MAPK) siRNA, confirming that p38 MAPK signaling is key to the inhibitory effects of ET-1 on Mas gene transcription.

Western blot analysis. Western blot analysis showed that ET-1 treatment for $4.5 \mathrm{~h}$ dose-dependently decreased the Mas protein level in human cardiomyocytes, which was blocked by BQ123 and PD169316, but not by BQ788 (Fig. 3). Similarly, human cardiomyocytes treated with ET-1 (30 nM) for $4.5 \mathrm{~h}$ showed a dose-dependent decrease in Ang-(1-7) binding on the cell membrane, which was blocked by BQ123 and PD169316, but not by BQ788 (Fig. 4). A previous study demonstrated that the phosphorylation and activation of $\mathrm{p} 38$ MAPK is involved in ET-1-induced biological effects (18). As shown in Fig. 5, western blot analysis showed that ET-1 treatment for $4.5 \mathrm{~h}$, dose-dependently increased phosphorylated p38 MAPK (Thr180/Tyr182) levels in human cardiomyocytes, which was blocked by BQ123, PD169316 and p38 MAPK siRNA, but not by BQ788. Fig. 5 also shows that the p38 siRNA knocked down $>70 \%$ of endogenous p38 MAPK expression. Taken together, the results suggest that ET-1 significantly decreased the density of ligand-binding Mas receptor on the cell membrane of human cardiomyocytes by downregulating Mas gene transcription via the ETA receptor by a p38 MAPK-dependent mechanism. 


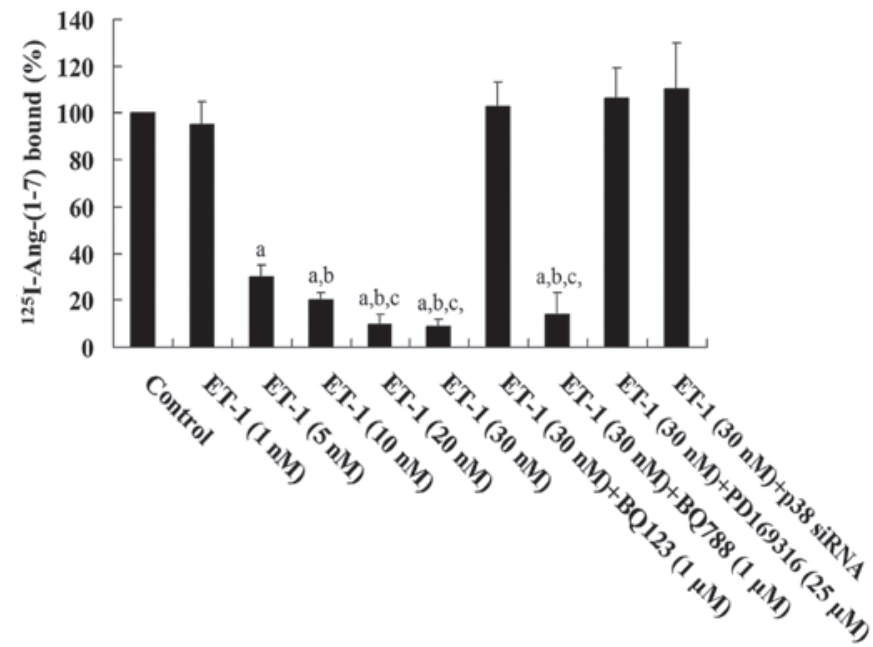

Figure 4. Saturation binding assay of Mas receptor on the cell membrane of human cardiomyocytes. Human cardiomyocytes were treated with ET-1 $(1,5,10,20$ and $30 \mathrm{nM})$ with or without BQ123 $(1 \mu \mathrm{M})$, BQ788 $(1 \mu \mathrm{M})$, PD169316 $(25 \mu \mathrm{M})$ or p38 mitogen-activated protein kinase siRNA for $4.5 \mathrm{~h}$. Twenty-four $\mathrm{h}$ later, saturation binding assays were conducted using increasing concentrations of ${ }^{125} \mathrm{I}$-Ang-(1-7) (1-22 nM) on cell membranes. A single-site receptor binding model provided the best fit for data analysis. Disintegrations per min (dpm) data were normalized against the cell number (per 20000 cells) and shown as a percentage of that of untreated contro cells (designated as $100 \%$ ). ${ }^{a} \mathrm{P}<0.05$ compared with untreated control cells; ${ }^{\mathrm{b}} \mathrm{P}<0.05$ compared with $5 \mathrm{nM}$ ET- 1 treatment and ${ }^{\mathrm{c}} \mathrm{P}<0.05$ compared with 10 nM ET-1 treatment.
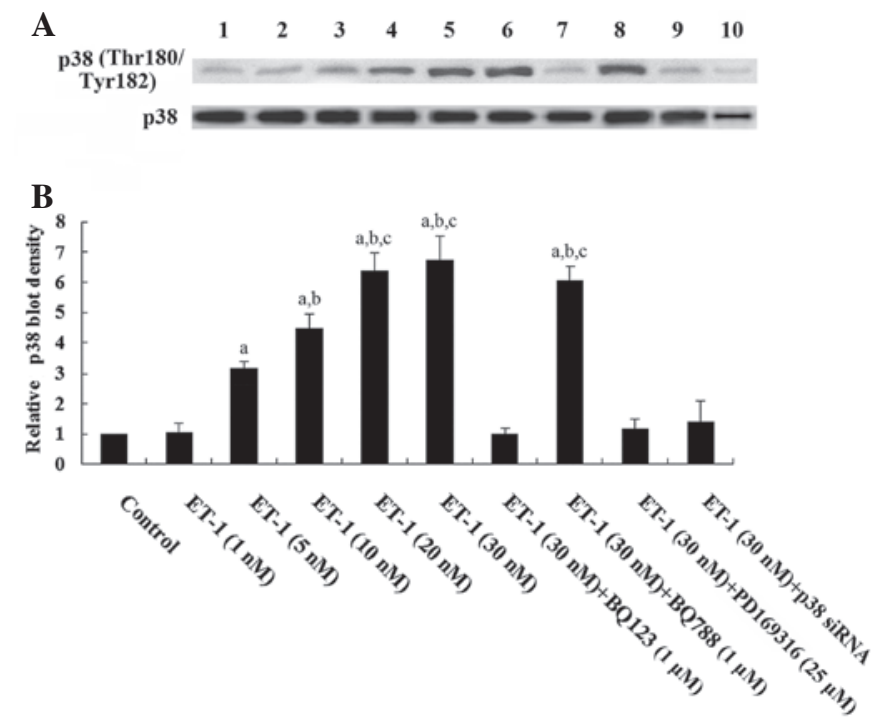

Figure 5. Western blot analysis of phosphorylated p38 mitogen-activated protein kinase (MAPK) levels in human cardiomyocytes. (A) Human cardiomyocytes were treated with ET-1 $(1,5,10,20$ and $30 \mathrm{nM})$ with or without BQ123 $(1 \mu \mathrm{M})$, BQ788 $(1 \mu \mathrm{M})$, PD169316 $(25 \mu \mathrm{M})$ or p38 MAPK siRNA for $4.5 \mathrm{~h}$. Lysates from untreated human cardiomyocytes were used as a control (lane 1). Concentrations of ET-1 were as follows: Lane 2, $1 \mathrm{nM}$; lane 3, $5 \mathrm{nM}$; lane 4, $10 \mathrm{nM}$; lane 5, $20 \mathrm{nM}$; lane 6, $30 \mathrm{nM}$; lane 7, $30 \mathrm{nM}$ and BQ123 $(1 \mu \mathrm{M})$; lane 8, $30 \mathrm{nM}$ and BQ788 $(1 \mu \mathrm{M})$; lane $9,30 \mathrm{nM}$ and PD169316 (25 $\mu \mathrm{M})$; lane 10, $30 \mathrm{nM}$ and p38 siRNA. $\beta$-actin blotting was used as a loading control. (B) Phosphorylated p38 (Thr180/Tyr182) and total p38 MAPK levels were measured by densitometry. The density of the phosphorylated p38 (Thr180/Tyr182) (pp38) MAPK blot was normalized against that of total p38 MAPK levels to obtain a relative density, which was expressed as fold changes to that of untreated control cells (designated as 1). ${ }^{a} \mathrm{P}<0.05$ compared with untreated control cells; ${ }^{b} \mathrm{P}<0.05$ compared with 5 nM ET-1 treatment and ${ }^{\mathrm{C}} \mathrm{P}<0.05$ compared with $10 \mathrm{nM}$ ET-1 treatment.

\section{Discussion}

Chronic myocardial stimulation by Ang II, the effector of the RAS, results in cardiac dysfunction (1). It is now accepted that the ACE2/Ang-(1-7)/Mas axis is able to counteract most of the deleterious actions of the ACE/Ang II/AT1 receptor axis, particularly in pathological conditions (11). ET-1, an important circulating hormone and a paracrine factor, is also involved in cardiac dysfunction (19). The present study was the first to demonstrate that ET-1 downregulates Mas expression in human cardiomyocytes.

ET-1 is released from cardiomyocytes and affects cardiac functions by either autocrine or paracrine mechanisms (20). A selective ETA receptor blocker, but not ETB receptor blocker, completely eliminated the effects of ET-1, indicating that ET-1 inhibited Mas expression via the ETA receptor. In addition, a selective p38 MAPK inhibitor or siRNA completely blocked the inhibitory effects of ET-1, indicating that ET-1 downregulates Mas expression by a p38 MAPK-dependent mechanism via the ETA receptor. Additional studies are needed to elaborate on the mechanisms of how ET-1 regulates Mas expression through p38 MAPK signaling.

The present study demonstrated that $10 \mathrm{nM}$ ET- 1 inhibited Mas gene transcription by $\sim 75 \%$ within $4.5 \mathrm{~h}$, suggesting that ET-1 is a strong negative regulator of the ACE2/Ang-(1-7)/ Mas axis. This finding supports results of a previous study whereby ET-1 treatment at $10 \mathrm{nM}$ for $12 \mathrm{~h}$ reduced ACE2 mRNA by $\sim 60 \%$ in cardiomyocytes (21). According to the findings of the present study, Mas is regulated more readily and may serve as a better therapeutic target compared with ACE2 in cardiomyocytes, as it responds to the ET-1 treatment more rapidly and to a greater extent. Thus alterations in the Mas expression level may be an acute cardiac response to the pathophysiological conditions, such as elevated plasma ET-1 levels.

Mas mediates most of the known cardioprotective effects of Ang-(1-7) (4). Elevated ET-1 levels may promote cardiac dysfunction by inhibiting ACE2 (21) and Mas expression, this will result in an increased concentration of Ang II, a recognized mediator of cardiomyocyte and cardiac dysfunction (1); a decreased concentration of Ang-(1-7), the protective peptide for cardiomyocytes, mainly by antagonizing the effects of Ang II; and a decreased Ang-(1-7)/Mas signaling due to a markedly reduced Mas expression. As the inhibitory effects of ET-1 on Mas expression is mediated through the ETA receptor, a selective ETA blocker may be beneficial for patients with cardiac dysfunction, which would be an interesting topic for future in vivo studies.

A number of studies have substantially supported the importance of the ACE2/Ang-(1-7)/Mas axis in renal function (22). As ET-1 is also involved in renal dysfunction (14), the regulatory effects of ET-1 on Mas expression would constitute an interesting topic in the field of kidney disease.

In conclusion, the present study has demonstrated that ET-1 downregulates Mas expression at the transcription level in human cardiomyocytes via the ETA receptor by a p38 MAPK-dependent mechanism. This study provides novel insights into the function of ET-1 and the Ang-(1-7)/Mas axis in cardiac pathophysiology. 


\section{References}

1. Domenighetti AA, Wang Q, Egger M, Richards SM, Pedrazzini T and Delbridge LM: Angiotensin II-mediated phenotypic cardiomyocyte remodeling leads to age-dependent cardiac dysfunction and failure. Hypertension 46: 426-432, 2005.

2. Mazzolai L, Pedrazzini T, Nicoud F, Gabbiani G, Brunner HR and Nussberger J: Increased cardiac angiotensin II levels induce right and left ventricular hypertrophy in normotensive mice. Hypertension 35: 985-991, 2000.

3. Domenighetti AA, Ritchie M, Smyth G, Pedrazzini T, Proietto J and Delbridge LMD: Gene expression profiling reveals distinct sets of genes altered during hormonally and metabolically induced cardiac hypertrophies. J Mol Cell Cardiol 37: 303, 2004

4. Ferreira AJ, Murça TM, Fraga-Silva RA, Castro CH, Raizada MK and Santos RA: New cardiovascular and pulmonary therapeutic strategies based on the Angiotensin-converting enzyme 2/angiotensin-(1-7)/mas receptor axis. Int J Hypertens 2012: 147825 2012.

5. Raizada MK and Ferreira AJ: ACE2: a new target for cardiovascular disease therapeutics. J Cardiovasc Pharmacol 50 112-119, 2007.

6. Vickers C, Hales P and Kaushik V, et al: Hydrolysis of biological peptides by human angiotensin-converting enzyme-related carboxypeptidase. J Biol Chem 277: 14838-14843, 2002.

7. Der Sarkissian S, Huentelman MJ, Stewart J, Katovich MJ and Raizada MK: ACE2: a novel therapeutic target for cardiovascular diseases. Prog Biophys Mol Biol 91: 163-198, 2006.

8. Rice GI, Thomas DA, Grant PJ, Turner AJ and Hooper NM: Evaluation of angiotensin-converting enzyme (ACE), its homologue ACE2 and neprilysin in angiotensin peptide metabolism. Biochem J 383: 45-51, 2004.

9. Stanziola L, Greene LJ and Santos RA: Effect of chronic angiotensin converting enzyme inhibition on angiotensin I and bradykinin metabolism in rats. Am J Hypertens 12: 1021-1029, 1999.

10. Gomes ER, Santos RA and Guatimosim S: Angiotensin-(1-7)mediated signaling in cardiomyocytes. Int J Hypertens 2012: 493129, 2012.
11. Ferreira AJ and Santos RA: Cardiovascular actions of angiotensin-(1-7). Braz J Med Biol Res 38: 499-507, 2005.

12. Zhang T, Li Z, Dang H, et al: Inhibition of Mas G-protein signaling improves coronary blood flow, reduces myocardial infarct size, and provides long-term cardioprotection. Am J Physiol Heart Circ Physiol 302: H299-H311, 2012.

13. Vignon-Zellweger N, Heiden S, Miyauchi T and Emoto N: Endothelin and endothelin receptors in the renal and cardiovascular systems. Life Sci 91: 490-500, 2012.

14. Shichiri M, Hirata Y, Ando K, et al: Plasma endothelin levels in hypertension and chronic renal failure. Hypertension 15: 493-496, 1990

15. Wei CM, Lerman A, Rodeheffer RJ, et al: Endothelin in human congestive heart failure. Circulation 89: 1580-1586, 1994.

16. Yazici M, Demircan S, Durna K and Sahin M: The relation between endothelin-1 levels and myocardial injury in chronic ischemic heart failure. Heart Vessels 20: 95-99, 2005.

17. Gironacci MM, Adamo HP, Corradi G, Santos RA, Ortiz P and Carretero OA: Angiotensin (1-7) induces MAS receptor internalization. Hypertension 58: 176-181, 2011.

18. Windischhofer W, Zach D, Fauler G, Raspotnig G, Köfeler H and Leis HJ: Involvement of Rho and p38 MAPK in endothelin-1-induced expression of PGHS-2 mRNA in osteoblast-like cells. J Bone Miner Res 17: 1774-1784, 2002.

19. Ohmae M: Endothelin-1 levels in chronic congestive heart failure. Wien Klin Wochenschr 123: 714-717, 2011.

20. Gallagher PE, Ferrario CM and Tallant EA: Regulation of ACE2 in cardiac myocytes and fibroblasts. Am J Physiol Heart Circ Physiol 295: H2373-H2379, 2008.

21. de Jonge HW, Dekkers DH, Houtsmuller AB, Sharma HS and Lamers JM: Differential signaling and hypertrophic responses in cyclically stretched vs endothelin-1 stimulated neonatal rat cardiomyocytes. Cell Biochem Biophys 47: 21-32, 2007.

22. Santos RA, Ferreira AJ, Verano-Braga $\mathrm{T}$ and Bader M: Angiotensin-converting enzyme 2, angiotensin-(1-7) and Mas: new players of the renin angiotensin system. J Endocrinol 216: R1-R17, 2013. 